\title{
Effect of the transdifferentiation of BECs into myofibroblasts on the pathogenesis of secondary cholestatic hepatic fibrosis
}

\author{
BING-FENG QIU, GUO-QIANG ZHANG, FANG-MING XU, QI XU and TANG XU
}

Department of Gastrointestinal Surgery, Zhoushan Hospital, Zhoushan, Zhejiang 316000, P.R. China

Received September 18, 2016; Accepted August 24, 2017

DOI: $10.3892 /$ etm.2019.7234

\begin{abstract}
The present study investigated the effect of the transdifferentiation of bile duct epithelial cells (BECs) into myofibroblasts on the pathogenesis of secondary cholestatic hepatic fibrosis and examined the underlying mechanisms. A total of 60 male rats with hepatic fibrosis were randomly divided into two groups: A secondary cholestatic hepatic fibrosis model group induced by ligation of the bile duct (BDL) and a sham group, which only underwent segregation of the choledochus. Rats in the BDL group were dynamically observed after week 1,2,3 and 4 post-BDL, and the remaining rats were sacrificed after week 5 to determine histological changes and hydroxyproline content. The cellular co-localization of cytokeratin (CK) $7 / \alpha$-smooth muscle actin (SMA) or $\alpha$-SMA/desmin was detected by immunofluorescence staining and laser confocal microscopy, while the protein expression levels of CK7, $\alpha$-SMA and desmin were determined by western blot analysis. Sirius red staining was also performed and quantified. The results revealed a significant correlation between the protein expression of CK7 and $\alpha-\operatorname{SMA}(\mathrm{r}=0.9692, \mathrm{P}<0.01)$. Furthermore, a predominant correlation between the number of cells stained for CK7/ $\alpha$-SMA and collagen deposition in liver tissues was identified, while the correlation of cells with co-localized $\alpha$-SMA and desmin was less pronounced. The transdifferentiation of BECs into myofibroblasts may be a key pathological factor in secondary cholestatic hepatic fibrosis formation.
\end{abstract}

\section{Introduction}

Hepatic fibrosis is a common pathological process of various chronic liver diseases and is considered a necessary pathological stage for the transformation of liver cirrhosis (1). Cholestasis and bile canaliculi hyperplasia are common

Correspondence to: Profeesor Guo-Qiang Zhang, Department of Gastrointestinal Surgery, Zhoushan Hospital, 739 Lincheng Street, Dinghai, Zhoushan, Zhejiang 316000, P.R. China

E-mail: zgqdoc1234@163.com

Key words: secondary cholestasis hepatic fibrosis, bile duct epithelial cells, epithelial to mesenchymal transition, bile duct ligation pathological changes in various types of chronic liver diseases, and chronic inflammation and fibrin deposition are important factors that promote the development of chronic liver disease (1). It was previously suggested that the pathogenesis of cholestatic liver fibrosis was associated with elevated circulating endotoxin levels, liver energy metabolism disorder, liver injury induced by oxygen free radical, liver hemodynamic disorder, ischemia of liver cells, calcium homeostasis disorder and liver cell necrosis and apoptosis induced by liver inflammation (1). However, the exact mechanism involved remains to be fully elucidated (1). In recent years, a number of scholars have investigated the vigorous proliferation of bile duct epithelial cells in the pathogenesis of cholestatic liver fibrosis $(2,3)$. Previous understanding of the role of hyperplastic small bile ducts in the pathogenesis of cholestatic liver fibrosis includes the following: i) They express cytokines, including interleukin (IL)-1, IL-6, IL-8 and interferon (IFN)-8 and IFN- $\alpha$ l cells in polymorphonuclear cells, $\mathrm{T}$ cells and circulating lymphocytes to the portal area, which induces inflammation of portal area; ii) they release platelet-derived growth factor (PDGF), transforming growth factor $\beta$, vascular endothelial growth factor, insulin-like growth factor and nerve growth factor to activate hepatic stellate cells, thereby inducing extracellular matrix deposition $(4,5)$. However, at present, it has been reported that bile duct epithelial cells can differentiate into $\alpha$-smooth muscle actin ( $\alpha$-SMA)-positive fibroblasts under certain conditions (6). Therefore, in the present study, a secondary cholestatic hepatic fibrosis rat model was prepared by ligation of the common bile duct. Bile duct epithelial cell proliferation, the expression of bile duct marker cytokeratin 7 (CK 7) and fibroblast marker $\alpha$-SMA-positive cells were dynamically observed to investigate the role of bile duct epithelial cell proliferation and its transdifferentiation into myofibroblasts in the pathogenesis of secondary cholestatic hepatic fibrosis.

\section{Materials and methods}

Animals. Male Sprague Dawley (SD) rats ( $n=60$; weight, 180-220 g; aged 6-8 weeks old) were purchased from the Experimental Animal Center of the Chinese Academy of Sciences (Shanghai, China; license no. SCXK, 2005-0006). Animal maintenance, modeling and observation were performed at the Experimental Animal Center of Shanghai University of Traditional Chinese Medicine (Shanghai, China). The rats had ad libitum access to food and water, 
were exposed to a 12-h light dark cycle and maintained in a temperature-controlled room $\left(20-25^{\circ} \mathrm{C}\right.$; humidity: $\left.40-70 \%\right)$. The animal protocol of the present study was approved by the Ethics Committee of Zhoushan Hospital (Zhoushan, China).

Reagents and instruments. Hydroxyproline (Hyp), which is used to construct standard curves, was purchased from Nacalai Testque Corp. (Tokyo, Japan). The protein quantitative reagent kit (Protein Quantitation Kit, cat. no. 500-0001) was purchased from Bio-Rad Laboratories, Inc. (Hercules, CA, USA). The monoclonal anti-CK7 antibody (cat. no. sc25721) and monoclonal anti-desmin antibody (cat. no. ab 8470) were purchased from Abcam (Cambridge, MA, USA). Monoclonal anti- $\alpha$-SMA antibody (cat. no. cbl171), anti-GADPH antibody (cat. no. KC-5G4; isotype immunoglobulin (Ig)G2 $\alpha$ ) was from Sigma-Aldrich (Merck KGaA, Darmstadt, Germany). Monoclonal anti-GADPH antibody (cat. no. KC-5G4) was purchased from Kangcheng Biotechnology (Guangzhou, China). Horseradish peroxidase (HRP)-labeled goat anti mouse antibody (cat. no. P6782) was purchased from Jingmei Biotech Corp. The western blot analysis marker was purchased from New England Biolabs, Inc. (Ipswich, MA, USA). The enhanced chemiluminescence (ECL) kit was from Pierce (Thermo Fischer Scientific, Inc., Waltham, MA, USA). Cy3 (cat. no. 7576) or fluorescein isothiocyanate (FITC) fluorescent-labeled secondary antibodies (cat. no. 76233) were purchased from Jackson Immunoresearch Laboratories, Inc. (West Grove, PA, USA). Alexa Fluor ${ }^{\circledR} 633$ goat anti-mouse IgG2a fluorescent secondary antibody was from Molecular Probes Inc. (7627; Thermo Fischer Scientific, Inc.). The TCS SP2 laser scanning confocal microscope was from Leica Microsystems (Wetzlar, Germany).

Grouping and model preparation. Rats $(n=60)$ were labeled and randomly divided into two groups: Sham-operated control group ( $n=10$, sham group) and bile duct ligation (BDL) group $(n=50)$. After intraperitoneal injection of pentobarbital sodium (Shanghai Haling Biotechnology Co., Ltd., Shanghai, China) $(50 \mathrm{mg} / \mathrm{kg})$, the abdominal skin of the rats was routinely disinfected, incised along the ventral midline and the choledochus was exposed. In the sham group, the choledochus was only segregated and the abdomen was closed. In the BDL group, the operation was performed according to a previously reported method (7). In brief, after double ligation at the distal and proximal end, the choledochus was sheared off in the middle and the abdomen was closed.

Sample collection and processing. Five rats in the sham group were randomly selected and sacrificed for sampling at the end of post-operative week one. Five rats in the BDL group were randomly selected and sacrificed for sampling at the end of post-operative weeks 1,2, 3 and 4. All of the remaining rats were sacrificed for sampling at the end of post-operative week 5. Under anesthesia performed as mentioned above, the abdominal cavities of all rats were opened, the gross morphology of the liver was observed, the liver was removed for the preparation of liver specimens. The abdominal aorta was then cut and death was confirmed by observation of complete dilation of pupils and absence of heart beat.
Observation of animals. The observation of animals included the color of skin and mucous membrane, death and gross morphology of the liver of rats on biopsy.

Hyp content determination in liver tissues. The method of Jamall et al (8) was used to determine Hyp in liver tissues.

Histological observation of livers. Liver tissues were fixed in $10 \%$ neutral formalin, paraffin-embedded and cut into sections. Following dewaxing and rehydration, the sections were routinely stained with hematoxylin and eosin (H\&E), and with Sirius red. The pathological changes of the liver tissues were observed under a light microscope. Sirius red staining results were analyzed using IPP software (version 6.0; Shanghai Liangruan Biotechnology Co., Ltd., Shanghai, China): Five visual fields (magnification, x200) were observed in each tissue slice, and using the software, the stained areas in the images were selected as areas of interest. The mean optical density (integrated optical density), divided by the total area of the same visual field, was determined.

CK7, $\alpha-S M A$ and desmin protein expression in liver tissues. Western blot analysis was used for detection of CK7, $\alpha$-SMA and desmin levels. Total protein was extracted and denatured at $95-100^{\circ} \mathrm{C}$ for $5 \mathrm{~min}$. Hepatic tissue $(100 \mathrm{~g})$ was placed into $1 \mathrm{ml}$ radioimmunoprecipitation assay lysis buffer $(0.88 \mathrm{~g}$ $\mathrm{NaCl}, 1 \mathrm{ml} \mathrm{NP}-40,1 \mathrm{ml}$ 10\% SDS, $1 \mathrm{ml}$ of $1 \mathrm{M}$ Tris (pH 7.2), $1 \mathrm{ml}$ of $0.5 \mathrm{M}$ EDTA, $1 \mathrm{ml}$ of $0.1 \mathrm{M}$ PMSF and deionized water was added to make up to $100 \mathrm{ml}$ ). Homogenate was placed in the ice bath 3 times at 13,333 x g for $10 \mathrm{sec}$ each at $4^{\circ} \mathrm{C}$. The homogenate of hepatic tissue was transferred to a PMSF centrifuge tube, and was centrifuge for $15 \mathrm{~min}$ at $4^{\circ} \mathrm{C}$ and 19,200 x g. The supernatant was collected, and Protein Quantification Kit-Rapid (Nanjing Jiancheng Co. Ltd., Nanjing, China) was used to determine the total protein concentration. Subsequently, protein $(50 \mu \mathrm{g} / \mathrm{lane})$ was separated by $10 \%$ SDS-PAGE and transferred onto a nitrocellulose membrane. Following blocking for $1 \mathrm{~h}$ at room temperature with Tris buffered saline (TBS) solution $[2.42 \mathrm{~g}$ of Tris; $29.2 \mathrm{~g}$ of sodium chloride, $900 \mathrm{ml}$ of Distilled water; TWEEN-20 and TBS (TTBS): $500 \mathrm{ml}$ of TBS, $0.5 \mathrm{ml}$ of TWEEN-20; $10 \mathrm{ml}$ of sealing solution TTBS, $0.5 \mathrm{k}$ of dried skimmed milk; $3.03 \mathrm{~g}$ of glycine; $14.4 \mathrm{~g}$ of SDS; $1 \mathrm{~g}$ of SDS or $10 \mathrm{ml}$ of $10 \% \mathrm{SDS}$; added with distilled water until 11 ], antibody working fluid was added (CK7, $\alpha$-SMA and desmin antibodies were all diluted at a ratio of 1:1,500), followed by incubation at $4{ }^{\circ} \mathrm{C}$ overnight. After washing, the film was incubated with HRP-conjugated secondary antibody $(1: 1,000)$ at room temperature for one hour. Following washing, the blots were developed with ECL reagent, exposed to X-ray film (Kangchen Company, Shanghai, China; cat. no. KC-5G4) and the blots were stripped and re-probed with GAPDH antibody (dilution, 1:5,000), which was added as the internal reference. The target bands in the negative film were analyzed using the Furi FR-980 biological electrophoresis imaging analysis system (Shanghai Furi Science \& Technology, Ltd., Shanghai, China) and the integral value of each band was read and recorded by the computer automatically. The ratio of the sample's integral value vs. the internal reference integral value was statistically analyzed. 
Immunofluorescence analysis of CK7/ $\alpha-S M A$ and $\alpha-S M A / d e s m i n$ co-localization in liver tissues. Frozen sections of liver tissues $(4 \mu \mathrm{m})$ were fixed with $4 \%$ paraformaldehyde after thawing at room temperature for $30 \mathrm{~min}$. The sections were washed with PBS three times for five min each. The sections were incubated with $3 \% \mathrm{H}_{2} \mathrm{O}_{2}$ for 3 min to eliminate endogenous peroxidase, blocked with 5\% calf serum (Boster Biological Technology Co., Ltd., Wuhan, China) for $30 \mathrm{~min}$ and then incubated with the first antibody at $37^{\circ} \mathrm{C}$ for $120 \mathrm{~min}$. Subsequent to washing with PBS three times for five min each, samples were incubated with the first fluorescent secondary antibody at $37^{\circ} \mathrm{C}$ for $60 \mathrm{~min}$ and then washed with PBS as above. The sections were then incubated with the second primary antibody at $37^{\circ} \mathrm{C}$ for $120 \mathrm{~min}$, washed with PBS as above, incubated with the second fluorescent secondary antibody at $37^{\circ} \mathrm{C}$ for 60 min and washed again with PBS as above. The sections were sealed with $50 \%$ glycerin and then observed under a laser confocal microscope where images were captured. In the experiment, the dilution of the first antibodies to CK7, $\alpha$-SMA and desmin was 1:100, and the dilution of the fluorescent secondary antibodies conjugated with fluorescein isothiocyanate and $\mathrm{Cy} 3$, and Alexa Fluor ${ }^{\circledR} 633$ goat anti-mouse $\operatorname{IgG} 2$ a was 1:200. The positive staining areas of CK7, $\alpha$-SMA, CK7/ $\alpha$-SMA and $\alpha$-SMA/desmin were analyzed by IPP software as described above.

Statistical analysis. SPSS 13.0 software (SPSS, Inc., Chicago, IL, USA) was used for all statistical analyses. Measurement data were expressed as the mean \pm standard deviation. One-way analysis of variance was used followed by the least-significant difference test and data at each time point were compared with data at the previous time point and in the normal group. Linear regression equations were determined to perform a correlation analysis on the association between two variables. $\mathrm{P}<0.05$ was considered to indicate a statistically significant difference.

\section{Results}

General condition of animals. Each animal was fed in a single cage. Nos. 1-10 were divided into the sham operation group and no animal succumbed to fatality; Nos. 11-60 were divided into the model group, no animals succumbed to fatality in week 1 . However, 1 rat (No. 17) succumbed to fatality in week 2, 3 rats (Nos. 22, 27 and 51) succumbed to fatality in week 3, 4 rats succumbed to fatality (Nos. 11, 17, 31 and 53) in week 4 and 7 rats (Nos. 12, 15, 18, 19, 25, 43 and 59) succumbed to fatality in week 5. Any animals that presented with extreme pain, refused to drink water and eat for more than $24 \mathrm{~h}$ were injected with $150 \mathrm{mg} / \mathrm{kg}$ of sodium pentobarbital to minimize animal suffering. None of the rats died in the sham group, while 15 rats died in the BDL group (death rate, $30 \%$ ). There was neither a significant difference in the skin and mucous membrane color, nor in the morphology and texture of the livers of the rats in the sham group at week one and five. In rats in the BDL group, the abdominal bulge gradually increased after model establishment, and the yellow staining of the mucous membrane and the icteric sclera were gradually deepened, which reached a

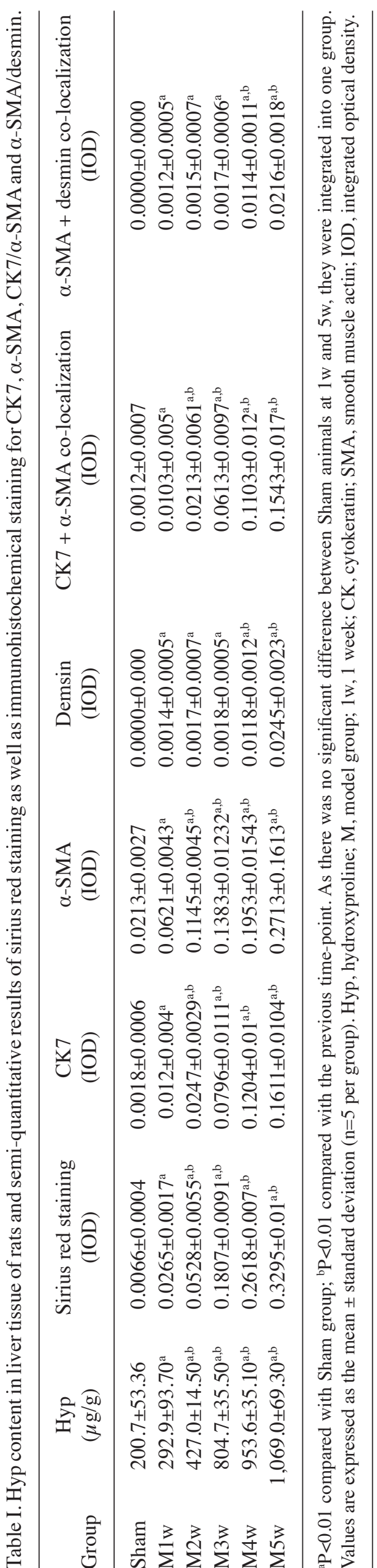




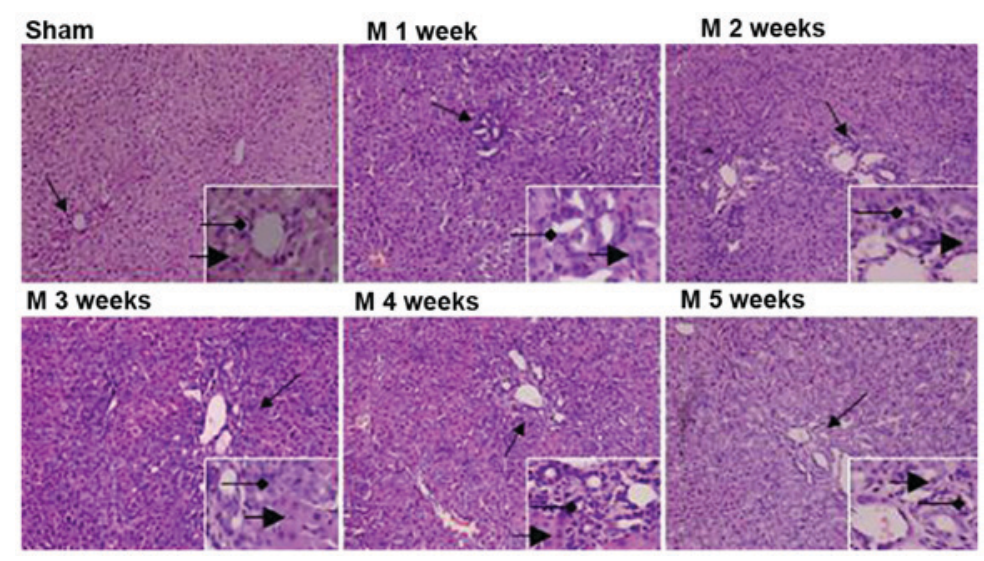

Figure 1. Hematoxylin and eosin staining of liver tissue of the rats (magnification, x200; magnified windows, x4 magnification). M, model group.

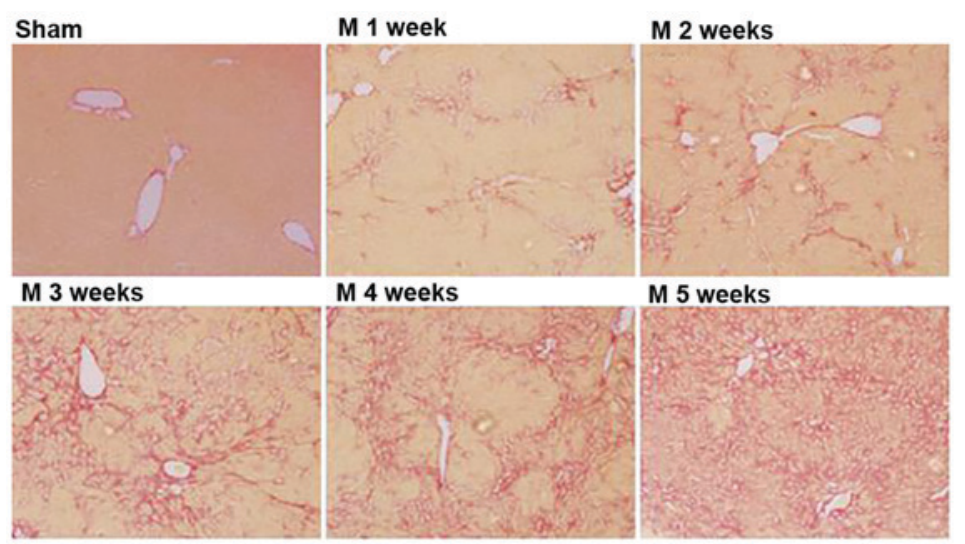

Figure 2. Sirius red staining of liver tissue of the rats (magnification, x100). M, model group.

peak at week two after BDL. The liver surface became rough and the texture became hard.

Hyp content variations in liver tissues. Compared with the sham group, the Hyp content gradually increased in liver tissues of rats in the BDL group (Sham $<$ model group at 1 week $(\mathrm{M} 1 \mathrm{w})<\mathrm{M} 2 \mathrm{w}<\mathrm{M} 3 \mathrm{w}<\mathrm{M} 4 \mathrm{w}<\mathrm{M} 5 \mathrm{w} ; \mathrm{P}<0.01$; Table I).

Liver histopathology. H\&E staining of liver tissues revealed the following: In the sham group, the structure of hepatic lobules was intact, the hepatic cords were arranged in neat rows and no inflammatory cell infiltration was detected at weeks one and five. In rats in the BDL group, with time progressing, hepatic parenchymal cells were significantly reduced, which gradually formed island-shaped structures of different sizes; furthermore, the degree of BEC hyperplasia gradually increased, a large number of small bile ducts with irregular arrangement were observed and a small amount of inflammatory cell infiltration was identified around the area (Fig. 1).

Sirius red staining revealed the following: No fibrous hyperplasia of the liver tissues was observed in the sham group at weeks one and five. In rats in the BDL group, fibrous hyperplasia of the liver tissues gradually increased after BDL $($ Sham $<\mathrm{M} 1 \mathrm{w}<\mathrm{M} 2 \mathrm{w}<\mathrm{M} 3 \mathrm{w}<\mathrm{M} 4 \mathrm{w}<\mathrm{M} 5 \mathrm{w}$; Table I and Fig. 2).
Expression of CK7 and $\alpha$-SMA is increased in liver tissues of $B D L$ rats. Compared with the sham group, the expression of CK7 and $\alpha$-SMA gradually increased in rat liver tissues in the BDL group (Sham $<\mathrm{M} 1 \mathrm{w}<\mathrm{M} 2 \mathrm{w}<\mathrm{M} 3 \mathrm{w}<\mathrm{M} 4 \mathrm{w}<\mathrm{M} 5 \mathrm{w}$; Figs. 3 and 4 ).

Furthermore, to perform a correlation analysis of CK7 and $\alpha$-SMA protein expression in rat liver tissues, the mean values of CK7/GAPDH and $\alpha$-SMA/GAPDH in the sham group ( $\mathrm{n}=5)$ and BDL group $(\mathrm{n}=5)$ at each time-point were statistically analyzed, and the correlativity of CK7/GAPDH and $\alpha$-SMA/GAPD in each group was analyzed by generating a linear regression equation. It was revealed that the expression of the two proteins was significantly and linearly correlated $(r=0.9860, \mathrm{P}<0.01$; Fig. 5).

Co-localization of $C K 7$ and $\alpha$-SMA in liver tissues of BDL rats is correlated with collagen deposition. The co-localization of CK7 and $\alpha$-SMA in rat liver tissues was assessed by immunofluorescence staining and observation under a laser scanning confocal microscope (Fig. 6, Table I). Only a minor amount of staining for CK7 (green) and for $\alpha$-SMA (blue) was observed in the sham group. In rats subjected to BDL, a gradual increase in cells stained for CK7 and $\alpha$-SMA was observed with increasing time. CK $7 / \alpha-S M A$ co-staining (cyan) also gradually increased. The correlation between the quantity of co-localization of CK7 and $\alpha$-SMA protein expression based on the co-stained area and the quantity of collagen deposition in rat liver tissues 

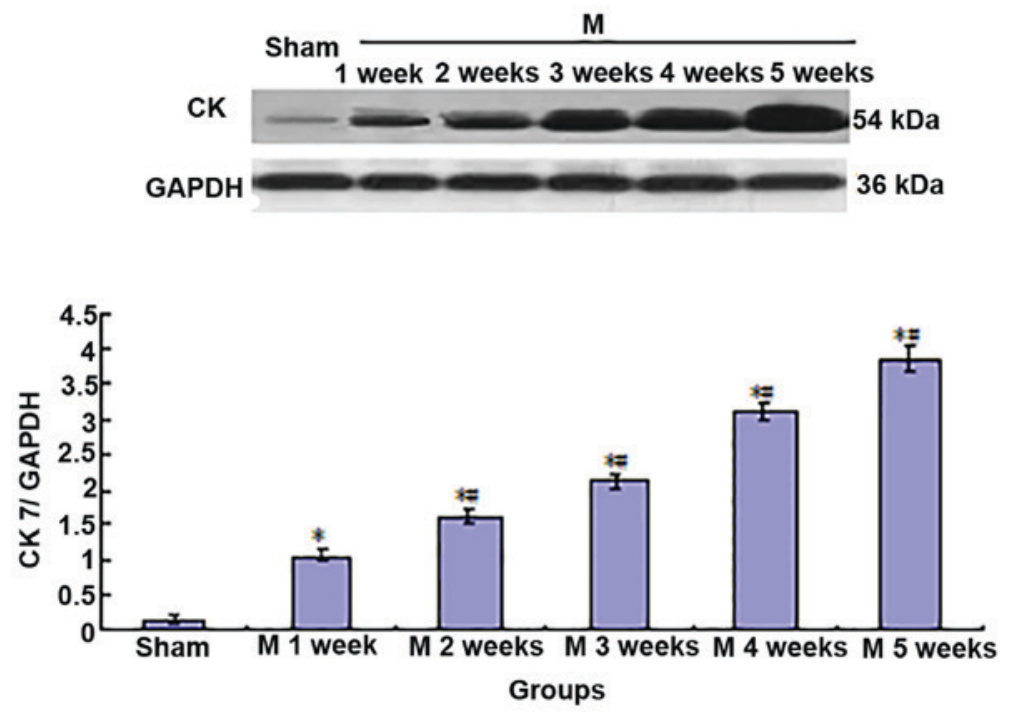

Figure 3. CK7 protein expression in liver tissue of the rats (western blot). ${ }^{*} \mathrm{P}<0.01$ vs. Sham group; ${ }^{\sharp} \mathrm{P}<0.01$ vs. previous week. CK, cytokeratin; $\mathrm{M}$, model group.

M
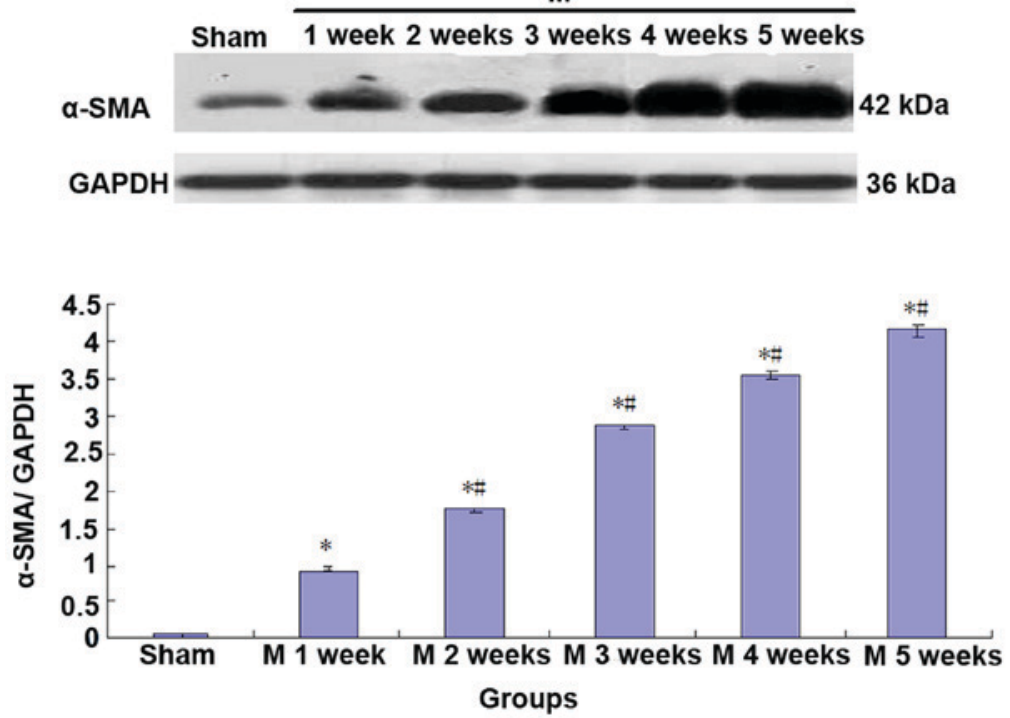

Figure 4. $\alpha$-SMA protein expression in liver tissue of the rats (western blot). M, model group. ${ }^{*} \mathrm{P}<0.01$ vs. Sham group; ${ }^{\text {}} \mathrm{P}<0.01$ vs. previous week. $\mathrm{M}$, model group; SMA, smooth muscle actin.

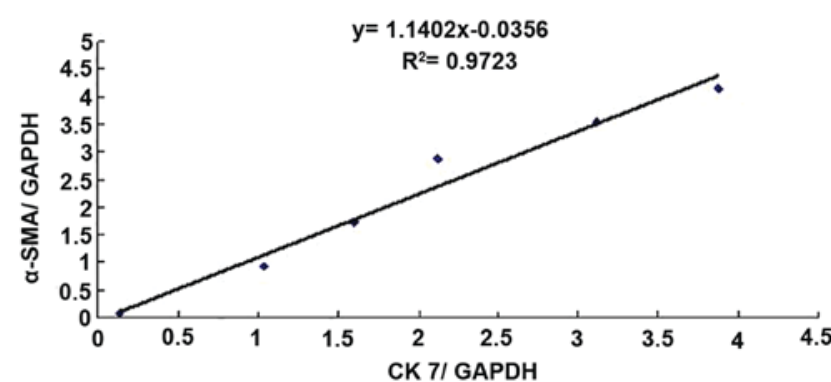

Figure 5. Correlation analysis of CK7 and $\alpha$-SMA protein expression in liver tissue of the rats with bile duct ligation (1-5 weeks). CK, cytokeratin; SMA, smooth muscle actin.

was analyzed using linear regression. The results indicated a significant and linear correlation ( $\mathrm{r}=0.9899, \mathrm{P}<0.01$; Fig. 7).
Expression of desmin protein in liver tissues. Compared with that in rats in the sham group, desmin expression was significantly increased in the livers of rats in the BDL group after 1 week $(\mathrm{P}<0.01)$. This expression was stable after 2 and 3 weeks (there were no significant differences among the values at M2w, M3w and M1w). However, the expression significantly increased after that $(\mathrm{M} 3 \mathrm{w}<\mathrm{M} 4 \mathrm{w}<\mathrm{M} 5 \mathrm{w} ; \mathrm{P}<0.01$; Fig. 8).

Co-localization of $\alpha$-SMA and desmin in liver tissues. The immunofluorescence co-localization of $\alpha$-SMA/desmin in rat liver tissues was observed under a laser scanning confocal microscope (Fig. 9, Table I). Only minor amounts of $\alpha$-SMA (red) and desmin (green) expression as well as cellular co-localization of $\alpha$-SMA/desmin (yellow) were identified in the sham group. Compared with the sham group, $\alpha$-SMAand desmin-expressing cells as well as $\alpha$-SMA/desmin co-localization were significantly increased after BDL at 


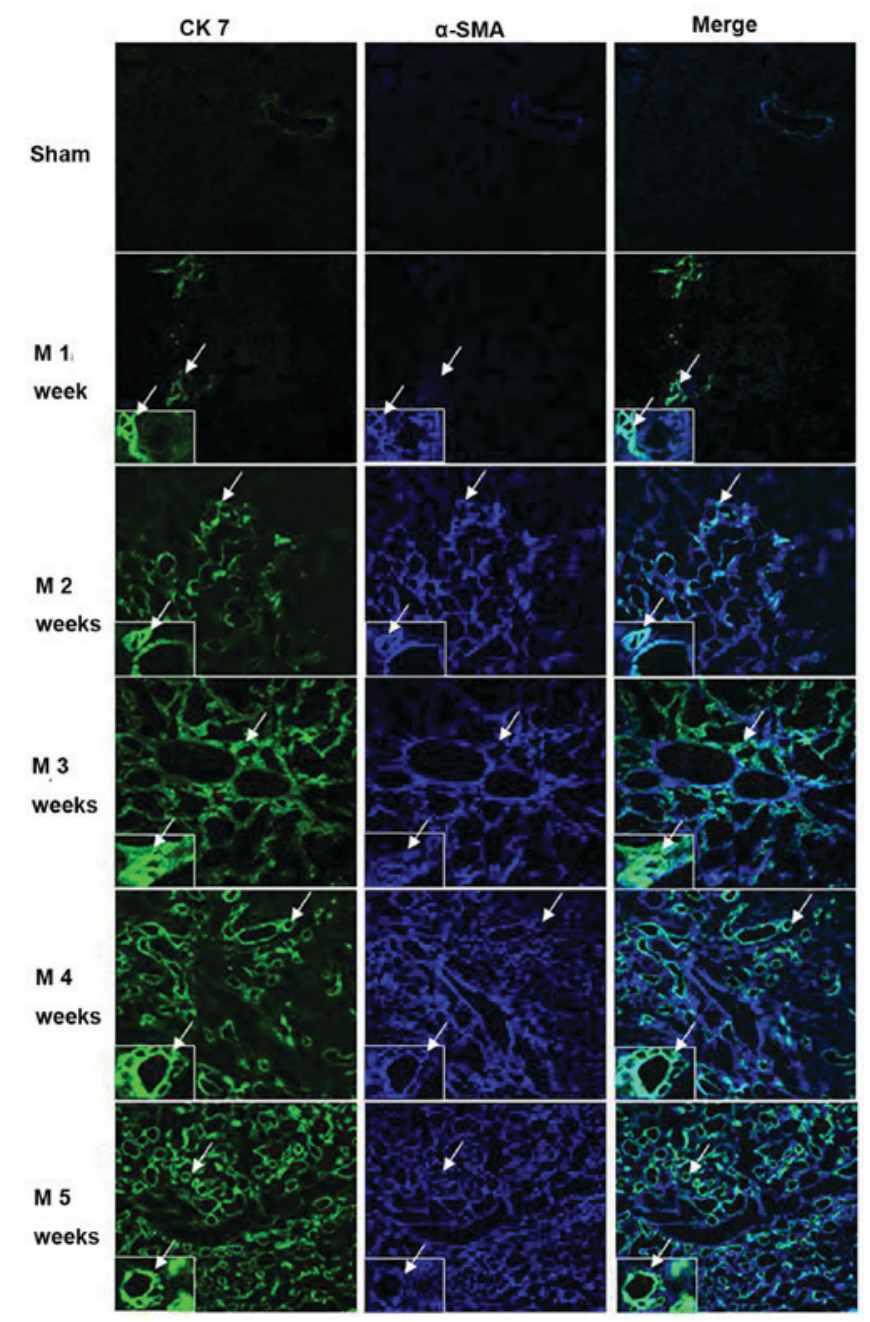

Figure 6. CK7/ $\alpha$-SMA immunofluorescent co-localization in liver tissue of rats (magnification, $\mathrm{x} 200$; magnified windows, $\mathrm{x} 4$ magnification). CK, cytokeratin; SMA, smooth muscle actin; M, model group.

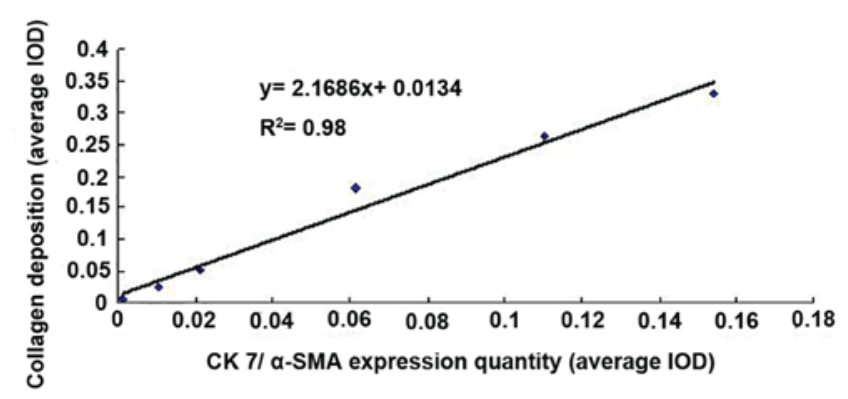

Figure 7. Correlation analysis of co-localized $\mathrm{Ck} 7$ and $\alpha$-SMA expression levels and collagen deposition in liver tissue of rats with bile duct ligation (1-5 weeks). IOD, integrated optical density; CK, cytokeratin; SMA, smooth muscle actin.

1 week $(\mathrm{P}<0.01)$. At weeks 2 and 3 , the expression of $\alpha$-SMA expression continuously increased, but desmin-expressing cells and $\alpha$-SMA/desmin co-localization were not significantly enhanced (no significant differences among M2w, M3w and M1w). At 4 and 5 weeks, $\alpha$-SMA-expressing cells continued to increase, and also the amount of desmin-expressing cells and cells with $\alpha$-SMA/desmin co-localization gradually increased $(\mathrm{M} 3 \mathrm{w}<\mathrm{M} 4 \mathrm{w}<\mathrm{M} 5 \mathrm{w} ; \mathrm{P}<0.01)$. However, no desmin protein expression was identified in the majority of $\alpha$-SMA-expressing cells.

\section{Discussion}

BDL is a model that has been widely used in the study of the pathological mechanism of cholestatic hepatic fibrosis (7). The results of the present study revealed that after BDL, $30 \%$ of the rats died in the model group within 5 weeks. The fatality of rats at weeks 2 and 3 was primarily due to shedding of ligation. Furthermore, the fatality of rats in weeks 4 and 5 were predominantly due to ascites and abdominal infection. The overall mortality rate was consistent with that reported by Ezure et al (7). Furthermore, the Hyp content in liver tissues gradually increased and reached five times that in the sham group at the end of the fifth week. Diffused BEC hyperplasia was identified in the H\&E-stained liver tissues. In addition, a certain amount of collagen fiber deposition was observed in the surroundings of the hyperplastic biliary epithelium, normal liver cells were markedly reduced, inflammation and necrosis were mild, and typical lesions of cholestatic hepatic fibrosis were formed.

Studies on patients and experimental animals have indicated that in the pathological state of cholestasis, significant hyperplasia of mesenchymal cells and the extracellular matrix were present, and a large amount of BEC hyperplasia was also identified (2). This hyperplasia of BECs may occur during the entire process of inflammatory damage of the liver and its repair. When the factors that induce hyperplasia of BECs were removed, BECs and the activated hepatic satellite cells became apoptotic, tissue metalloproteinase activity increased, and fibrosis and ductular hyperplasia faded away (3). Due to its close association with liver fibrosis formation, BEC hyperplasia is considered to be the pacemaker of portal tract fibrosis (2), as well as the key pathological link to cholestatic hepatic fibrosis formation.

Although the important role of BEC hyperplasia in the pathogenesis of cholestatic hepatic fibrosis is widely recognized, the exact mechanism has remained elusive (2). A large number of studies have demonstrated that during the generation of organ fibrosis, the epithelial cell phenotype may be transformed into a myofibroblast phenotype, a process known as epithelial to mesenchymal transition (EMT) $(9,10)$. In addition, the phenotypic transformation of this cell type has been considered to be the key pathological link in the pathogenesis of fibrosis of the kidney, lung, liver and other organs (11-13). In BDL rats, the expression of vimentin, the characteristic phenotype marker of mesenchymal cells, and the expression of protein $\alpha$-SMA, the characteristic phenotype marker of myofibroblasts, were identified in a large number of hyperplastic BECs $(6,14)$. Furthermore, the expression of fibroblast-specific protein-1 was detected in BECs of liver tissues of patients with primary cholestatic cirrhosis $(15,16)$. The mechanisms associated with the pathology and progression of numerous chronic liver diseases, including biliary atresia, were also identified to be associated with the EMT phenomenon of BECs $(17,18)$. In addition, transforming growth factor- $\beta 1$ was reported to stimulate the differentiation of BECs into mesenchymal cells in vitro (19). 
M

\section{Sham 1 week 2 weeks 3 weeks 4 weeks 5 weeks}

Desmin

53 kDa
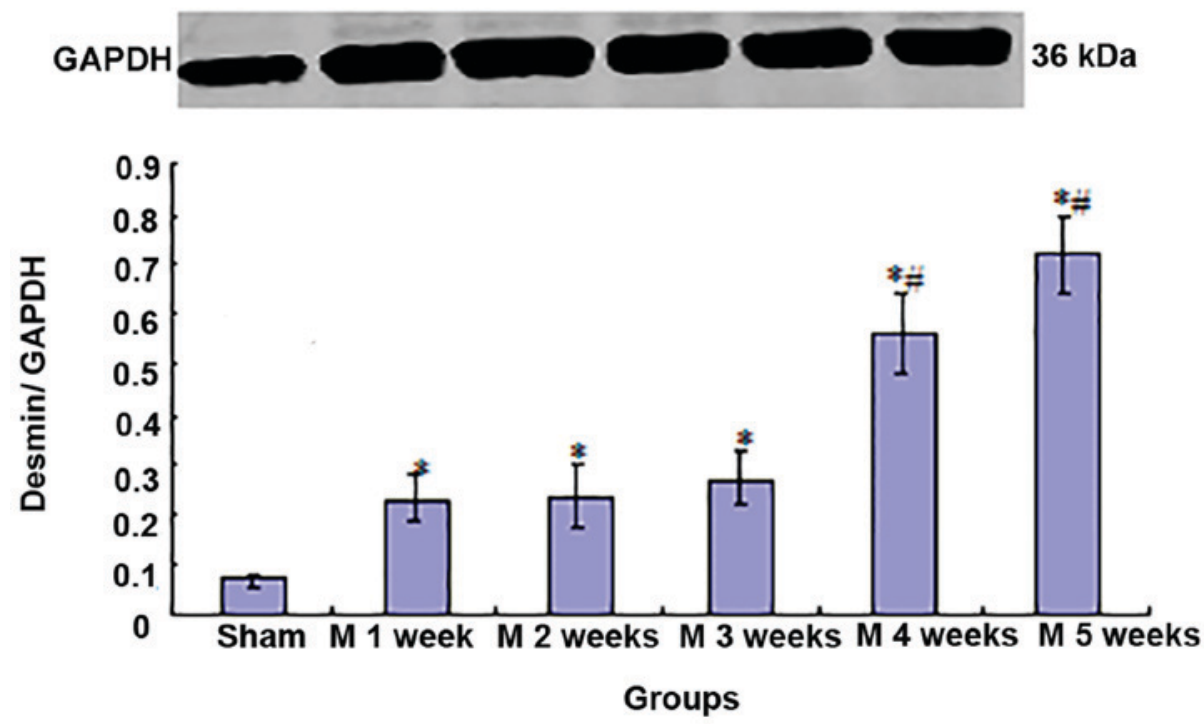

Figure 8. Desmin protein expression in liver tissue of rats determined by western blot analysis. ${ }^{*} \mathrm{P}<0.01$ vs. Sham group; ${ }^{\sharp} \mathrm{P}<0.01$ vs. previous week. M, model group.

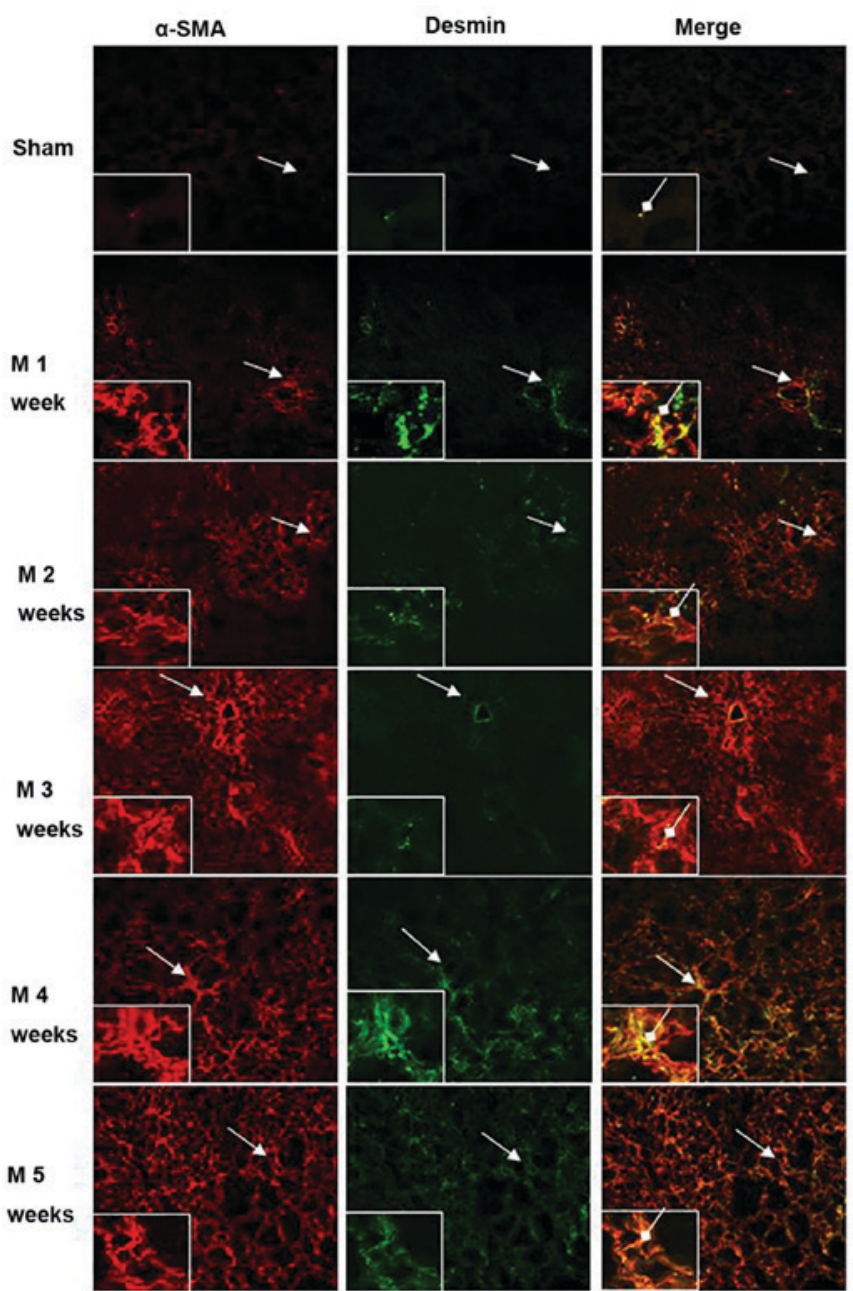

Figure 9. $\alpha$-SMA/desmin immunofluorescent co-location in liver tissue of rats (magnification, x200; magnified window, x4 magnification). M, model group.
In the present study, co-localization of BEC marker CK7 (20) and myofibroblast marker $\alpha$-SMA (21) by immunofluorescence detection revealed that after BDL, CK7- and $\alpha$-SMA-expressing cells, as well as cellular co-localization of the two proteins CK7 and $\alpha$-SMA were gradually increased. In addition, the expression of these two proteins in liver tissue of the model at different time-points was significantly correlated, suggesting that the development of liver fibrosis in BDL rats was associated with the transdifferentiation of hyperplastic BECs into myofibroblasts.

Desmin is specifically expressed in activated hepatic satellite cells (22). In the present study, western blot analysis and immunofluorescence microscopy of CK 7 and $\alpha$-SMA revealed that in BDL in rats, only a small amount of desmin protein expression was present and desmin/ $\alpha$-SMA co-localization in cells was infrequent after 1-3 weeks. However, after 4 and 5 weeks, the expression of desmin protein and cellular desmin/ $\alpha$-SMA co-localization gradually increased, while most of the $\alpha$-SMA-expressing cells did not express desmin. This suggested that at 1-3 weeks following BDL, and among the large number of $\alpha$-SM-expressing fibroblasts, only a small amount was derived from activated satellite cells. At 4 and 5 weeks, the proliferation and activation of satellite cells was increased compared with that at 1-3 weeks. However, most of the $\alpha$-SMA-expressing myofibroblasts may still have been mainly derived from the transdifferentiation of hyperplastic BECs.

In conclusion, the results of the present study indicated that transdifferentiation of hyperplastic BECs into myofibroblasts may be one of the key factors in the formation of cholestatic hepatic fibrosis.

\section{Acknowledgements}

Not applicable. 


\section{Funding}

No funding was received.

\section{Availability of data and materials}

The datasets used and/or analysed during the present study available from the corresponding author on reasonable request.

\section{Authors' contributions}

BFQ provided substantial contributions to the conception and design of the work, GQZ, FMX, QX and TX contributed to the acquisition, analysis, and interpretation of data. BFQ drafted the manuscript and GQZ, FMX, QX and TX revised the manuscript critically for important intellectual content. BFQ, GQZ, FMX, QX and TX provided final approval of the version to be published.

\section{Ethics approval and consent to participate}

The animal protocol of the present study was approved by the Ethics Committee of Zhoushan Hospital (Zhoushan, China).

\section{Patient consent for publication}

Not applicable.

\section{Competing interest}

The authors declare that they have no competing interests.

\section{References}

1. Westbrook RH, Dusheiko G and Williamson C: Pregnancy and liver disease. J Hepatol 64: 933-945, 2016.

2. Wells RG: The portal fibroblast: Not just a poor man's stellate cell. Gastroenterology 147: 41-47, 2014

3. Glaser S, Han Y, Francis H and Alpini G: Melatonin regulation of biliary functions. Hepatobiliary Surg Nutr 3: 35-43, 2014.

4. Lazaridis KN and LaRusso NF: The cholangiopathies. Mayo Clin Proc 90: 791-800, 2015.

5. Beuers U, Trauner M, Jansen P and Poupon R: New paradigms in the treatment of hepatic cholestasis: From UDCA to FXR, PXR and beyond. J Hepatol 62 (1 Suppl): S25-S37, 2015.
6. Xia JL, Dai C, Michalopoulos GK and Liu Y: Hepatocyte growth factor attenuates liver fibrosis induced by bile duct ligation. Am J Pathol 168: 1500-1512, 2006.

7. Ezure T, Sakamoto T, Tsuji H, Lunz JG III, Murase N, Fung JJ and Demetris AJ: The development and compensation of biliary cirrhosis in interleukin-6-deficient mice. Am J Pathol 156: $1627-1639,2000$

8. Jamall IS, Finelli VN and Que Hee SS: A simple method to determine nanogram levels of 4-hydroxyproline in biological tissues. Anal Biochem 112: 70-75, 1981.

9. Nieto MA, Huang RY, Jackson RA and Thiery JP: EMT: 2016. Cell 166: 21-45, 2016.

10. Anders HJ and Schaefer L: Beyond tissue injury-damage-associated molecular patterns, toll-like receptors, and inflammasomes also drive regeneration and fibrosis. J Am Soc Nephrol 25: 1387-1400, 2014.

11. Benali SL, Lees GE, Castagnaro M and Aresu L: Epithelial mesenchymal transition in the progression of renal disease in dogs. Histol Histopathol 29: 1409-1414, 2014.

12. Della Latta V, Cecchettini A, Del Ry S and Morales MA: Bleomycin in the setting of lung fibrosis induction: From biological mechanisms to counteractions. Pharmacol Res 97: 122-130, 2015.

13. Lee SJ, Kim KH and Park KK: Mechanisms of fibrogenesis in liver cirrhosis: The molecular aspects of epithelial-mesenchymal transition. World J Hepatol 6: 207-216, 2014.

14. Robertson H, Kirby JA, Yip WW, Jones DE and Burt AD: Biliary epithelial-mesenchymal transition in posttransplantation recurrence of primary biliary cirrhosis. Hepatology 45: 977-981, 2007.

15. Omenetti A, Porrello A, Jung Y, Yang L, Popov Y, Choi SS, Witek RP, Alpini G, Venter J, Vandongen HM, et al: Hedgehog signaling regulates epithelial-mesenchymal transition during biliary fibrosis in rodents and humans. J Clin Invest 118: 3331-3342, 2008.

16. Schulze F, Schardt K, Wedemeyer I, Konze E, Wendland K, Dirsch O, Töx U, Dienes HP and Odenthal M: Epithelial-mesenchymal transition of biliary epithelial cells in advanced liver fibrosis. Verh Dtsch Ges Pathol 91: 250-256, 2007 (In German).

17. Park SM: The crucial role of cholangiocytes in cholangiopathies. Gut Liver 6: 295-304, 2012.

18. Lee SJ, Park JB, Kim KH, Lee WR, Kim JY, An HJ and Park KK: Immunohistochemical study for the origin of ductular reaction in chronic liver disease. Int J Clin Exp Pathol 7: 4076-4085, 2014.

19. Sato Y, Harada K, Ozaki S, Furubo S, Kizawa K, Sanzen T, Yasoshima M,Ikeda H, Sasaki M and Nakanuma Y: Cholangiocytes with mesenchymal features contribute to progressive hepatic fibrosis of the polycystic kidney rat. Am J Pathol 171: 1859-1871, 2007.

20. Weiss MC and Strick-Marchand H: Isolation and characterization of mouse hepatic stem cells in vitro. Semin Liver Dis 23: 313-324, 2003.

21. Tsukada S, Parsons CJ and Rippe RA: Mechanisms of liver fibrosis. Clin Chim Acta 364: 33-60, 2006.

22. Tsutsumi M, Takada A and Takase S: Characterization of desmin-pvsitive rat liver sinusoidal cells. Hepatology 7: 277-228, 1987. 